Pacific Journal of Mathematic 


\section{INVERSE LIMITS OF INDECOMPOSABLE CONTINUA}

\section{J. H. REED}

Let $\left\{X_{\lambda}, f_{\lambda \mu}, \Lambda\right\}$ denote an inverse limit system of continua, with inverse limit space $X_{\infty}$. Capel has shown that if each $X_{\lambda}$ is an arc (simple closed curve), then $X_{\infty}$ is an arc (simple closed curve) provided that $\Lambda$ is countable and the bonding maps are monotone and onto. It is shown in this paper that a similar result holds when each $X_{\lambda}$ is a pseudoarc. In fact, the restrictions that the bonding maps be monotone and onto may be deleted.

Two theorems are proved which lead to this result. First, it is shown that if the maps of an inverse system of indecomposable continua are onto, then the limit space is an indecomposable continuum. Next, it is shown that with no restrictions on the bonding maps, a similar statement is true for hereditarily indecomposable continua.

1. Definitions and notation. All spaces are assumed to be Hausdorff. The notation $\left\{X_{\lambda}, f_{\lambda \mu}, \Lambda\right\}$ represents an inverse limit system with factor spaces $X_{\lambda}$, bonding maps $f_{\lambda \mu}$ and directed set $A$. The inverse limit space of the system $\left\{X_{\lambda}, f_{\lambda \mu}, \Lambda\right\}$ is denoted by $X_{\infty}$. Definitions of these terms may be found in [2]. For each $\lambda \in A, \Pi_{\lambda}$ denotes the projection function of $P_{\lambda \in A} X_{\lambda}$ onto $X_{\lambda}$, restricted to $X_{\infty}$.

A continuum is a compact connected Hausdorff space. A continuum is indecomposable if it cannot be expressed as the union of two proper subcontinua. It is hereditarily indecomposable if each of its subcontinua is indecomposable.

A chain is a finite collection of open sets $U_{1}, \cdots, U_{n}$ such that $U_{i} \cap U_{j} \neq \varnothing$ if and only if $|i-j| \leqq 1$. A space $X$ is said to be chainable if each open covering of $X$ has a chain refinement. Hence a chainable space is a continuum.

If $X$ is a metric space and $U_{1}, \cdots, U_{n}$ is a chain covering of $X$ such that for some $\varepsilon>0$, diameter $U_{i}<\varepsilon$ for $i=1, \cdots, n$, then the chain $U_{1}, \cdots, U_{n}$ is said to be an $\varepsilon$-chain covering of $X$. A metric space $X$ is snakelike if for each $\varepsilon>0$, there exists an $\varepsilon$-chain covering of $X$.

2. Preliminary results, The following basic results will be needed. When proofs are omitted, they may be found in the references as indicated.

2-1. Let $\left\{X_{\lambda}, f_{\lambda \mu}, \Lambda\right\}$ be an inverse system of compact metric spaces, where $\Lambda$ is countable. Then $X_{\infty}$ is a metric space. 
Proof. Since $\Lambda$ is countable, we may choose a countable, linearly ordered cofinal subset $\Lambda^{\prime}$ of $\Lambda$, such that if $\lambda_{i}, \lambda_{j} \in \Lambda^{\prime}$ and $i<j$, then $\lambda_{i}<\lambda_{j}$. Let $d_{i}$ be the diameter of $X_{\lambda_{i}}$. Then a metric for $P_{\lambda_{i} \in 1^{\prime}} X_{\lambda_{i}}$ is defined as follows: For $\left\{x_{\lambda_{i}}\right\}$ and $\left\{y_{\lambda_{i}}\right\} \in P_{\lambda_{i} \in A^{\prime}} X_{\lambda_{i}}$, set

$$
\rho\left(\left\{x_{\lambda_{i}}\right\},\left\{y_{\lambda_{i}}\right\}\right)=\sum_{i=1}^{\infty} 2^{-i} d_{i}^{-1} \rho_{i}\left(x_{\lambda_{i}}, y_{\lambda_{i}}\right)
$$

where $\rho_{i}$ is the metric on $X_{\lambda_{i}}$. Then since $\rho$ is a metric on $P_{\lambda_{i} \in 1^{\prime}} X_{\lambda_{i}}$, it is also a metric for $X_{\infty}^{\prime}$. Thus $X_{\infty}$ is a metric space, since $X_{\infty}$ is homeomorphic to $X_{\infty}^{\prime}$ by $[2,2.11]$.

2-2. Let $\left\{X_{\lambda}, f_{\lambda \mu}, \Lambda\right\}$ be an inverse system of continua, with limit space $X_{\infty}$. If $X_{2}$, is chainable for each $\lambda \in \Lambda$, then $X_{\infty}$ is chainable.

Proof. $X_{\infty}$ is a continuum by [2, 2.5 and 2.10]. Mardesic [4] has shown that $X_{\infty}$ is chainable if each $f_{\lambda, \mu}$ is onto. We use this result here.

Let $A_{\lambda}=\Pi_{\lambda}\left(X_{\infty}\right)$ and $g_{\lambda_{\mu}}=f_{\lambda_{\mu}} \mid A_{\lambda}$. Then by $[2,2.8],\left\{A_{\lambda}, g_{\lambda \mu}, \Lambda\right\}$ is an inverse system, each $g_{\lambda \mu}$ is onto and the limit space $A_{\infty}$ of this system is $X_{\infty}$. Since each subcontinuum of a chainable continuum is chainable, $A_{\lambda}$ is chainable for each $\lambda \in \Lambda$. Thus $A_{\infty}=X_{\infty}$ is chainable by [4].

\section{Inverse limits of indecomposable continua.}

3-1. Theorem. Let $\left\{X_{\lambda}, f_{\lambda \mu}, \Lambda\right\}$ be an inverse limit system of indecomposable continua, where each function $f_{\lambda \mu}$ is onto. Then the inverse limit space $X_{\infty}$ is an indecomposable continuum.

Proof. $X_{\infty}$ is a continuum by [2, 2.5 and 2.10]. Suppose $X_{\infty}$ is decomposable, i.e., suppose there exist proper subcontinua $H$ and $K$ of $X_{\infty}$ such that $X_{\infty}=H \cup K$.

We show first that there exists $\gamma \in \Lambda$ such that $\Pi_{\gamma}(H) \varsubsetneqq X_{\gamma}$. If not, then for all $\lambda \in A, \Pi_{\lambda}(H)=X_{\lambda}$. Let $\left\{x_{\lambda}\right\} \in X_{\infty}$ such that $\left\{x_{\lambda}\right\} \notin H$, and let $N$ be any neighborhood of $\left\{x_{\lambda}\right\}$. Then there exist indices $\lambda_{i}, i=1,2, \cdots n$ and neighborhoods $N_{\lambda_{i}}$ of each $x_{\lambda_{i}} \in X_{\lambda_{i}}$ such that $N=\left\{\left\{y_{\lambda}\right\} \in X_{\infty} \mid y_{\lambda_{i}} \in N_{\lambda_{i}}, i=1,2, \cdots, n\right\}$. Since $\Lambda$ is a directed set, there exists $\lambda_{0} \in \Lambda$ such that $\lambda_{0}>\lambda_{i}, i=1,2, \cdots, n$. Let $U_{\lambda_{0}}=\bigcap_{i=1}^{n} f_{\lambda_{0} \lambda_{i}}^{-1}\left(N_{\lambda_{i}}\right)$. Then $U_{\lambda_{0}}$ is an open subset of $X_{\lambda_{0}}$ and $N=\left\{\left\{y_{\lambda}\right\} \in X_{\infty} \mid y_{\lambda_{0}} \in U_{\lambda_{0}}\right\}$. Now since $\Pi_{\lambda}(H)=X_{\lambda}$ for all $\lambda \in \Lambda$, there exists a point $\left\{x_{\lambda}^{\prime}\right\} \in H$ such that $\Pi_{\lambda_{0}}\left(\left\{x_{\lambda}^{\prime}\right\}\right) \in U_{\lambda_{0}}$, and hence $\left\{x_{\lambda}^{\prime}\right\} \in N$. Thus $\left\{x_{\lambda}\right\}$ is a limit point of $H$. This is a contradiction, since $H$ is closed and $\left\{x_{\lambda}\right\} \notin H$. Thus there exists $\gamma \in \Lambda$ such that $\Pi_{\gamma}(H) \varsubsetneqq X_{\gamma}$. 
Similarly, there exists $\beta \in \Lambda$ such that $\Pi_{\beta}(K) \varsubsetneqq X_{\beta}$. Since $\Lambda$ is a directed set, there exists $\delta \in \Lambda$ such that $\delta>\beta$ and $\delta>\gamma$. We show that $\Pi_{\delta}(H) \varsubsetneqq X_{\delta}$. For if $\Pi_{\delta}(H)=X_{\delta}$, then $\Pi_{\gamma}(H)=f_{\delta \gamma}\left(X_{\delta}\right)$ since $f_{\delta \gamma} \Pi_{\delta}=\Pi_{\gamma}$. But $f_{\delta \gamma}$ is onto and hence $f_{\delta \gamma}\left(X_{\delta}\right)=X_{\gamma}$. Thus we have $\Pi_{\gamma}(H)=X_{\gamma}$, a contradiction. Therefore, $\Pi_{\delta}(H) \varsubsetneqq X_{\delta}$, and similarly $\Pi_{\delta}(K) \varsubsetneqq X_{\delta}$.

Now since $\Pi_{\delta}$ is continuous, $\Pi_{\delta}(H)$ and $\Pi_{\delta}(K)$ are subcontinua of $X_{\delta}$. Also, $\Pi_{\delta}\left(X_{\infty}\right)=X_{\delta}[2,2.6]$. Therefore

$$
X_{\delta}=\Pi_{\delta}\left(X_{\infty}\right)=\Pi_{\delta}(H \cup K)=\Pi_{\delta}(H) \cup \Pi_{\delta}(K) .
$$

This is a contradiction, since $X_{\delta}$ is indecomposable.

3-2. Theorem. Let $\left\{X_{\lambda}, f_{\lambda \mu}, \Lambda\right\}$ be an inverse limit system of hereditarily indecomposable continua. Then the limit space $X_{\infty}$ is hereditarily indecomposable.

Proof. $X_{\infty}$ is a continuum by [2,2.5 and 2.10]. Let $M$ be any subcontinuum of $X_{\infty}$. We show that $M$ is indecomposable.

Let $M_{\lambda}=\Pi_{\lambda}(M)$ and let $g_{\lambda \mu}=f_{\lambda_{\mu}} \mid M_{\lambda}$. Each $M_{\lambda}$ is a subcontinuum of $X_{\lambda}$ and hence indecomposable. Also, by [2,2.8], $\left\{M_{\lambda}, g_{\lambda, \mu}, \Lambda\right\}$ is an inverse system, each $g_{\lambda \mu}$ is onto and the limit space $M_{\infty}$ of this system is $M$. Thus $M$ is indecomposable by Theorem $3-1$.

3.-3. CoRollary. Let $\left\{X_{\lambda}, f_{\lambda \mu}, \Lambda\right\}$ be an inverse limit system of hereditarily indecomposable continua. Then the inverse limit space $X_{\infty}$ is an indecomposable continuum.

Corollary 3-3 shows that Theorem 3-1 remains valid when the functions $f_{\lambda \mu}$ are not onto, provided that each $X_{\lambda}$ is hereditarily indecomposable.

3-4. THeorem. Let $\left\{X_{\lambda}, f_{\lambda \mu}, \Lambda\right\}$ be an inverse limit system of pseudo-arcs. Let $X_{\infty}$ be the inverse limit space. Then $X_{\infty}$ is a chainable, hereditarily indecomposable continuum. If $\Lambda$ is countable and $X_{\infty}$ is nondegenerate, then $X_{\infty}$ is a pseudo-arc.

Proof. $X_{\infty}$ is a hereditarily indecomposable continuum by Theorem $3-2$. For metric spaces, the definitions of chainable and snakelike continua are equivalent. Thus each $X_{\lambda}$ is chainable and hence $X_{\infty}$ is chainable by $2-2$.

If $\Lambda$ is countable, then $X_{\infty}$ is a metric space by $2-1$, and thus snakelike. Therefore, $X_{\infty}$ is a hereditarily indecomposable snakelike continuum, and hence a pseudo-arc if it is nondegenerate [1]. 


\section{REFERENCES}

1. R. H. Bing, Concerning Hereditarily Indecomposable Continua, Pacific J. Math. 1 (1951), 43-51.

2. C. E. Capel, Inverse limit spaces, Duke Math. J. 21 (1954), 233-245.

3. S. Eilenberg and N. Steenrod, Foundations of Algebraic Topology, Princeton, 1952.

4. S. Mardesic, Chainable Continua and Inverse Limits, Glasnik Mat. Fizicki Astronomski, Zagreb (1959), 219-232.

Received June 7, 1966.

University of SoUth Florida 


\section{PACIFIC JOURNAL OF MATHEMATICS}

\section{H. ROYDEN}

Stanford University

Stanford, California

\author{
J. P. JANS \\ University of Washington \\ Seattle, Washington 98105
}

\section{EDITORS}

\author{
J. DugundJI \\ Department of Mathematics \\ Rice University \\ Houston, Texas 77001 \\ Richard ARENS \\ University of California \\ Los Angeles, California 90024
}

\section{ASSOCIATE EDITORS}
E. F. BECKENBACH
B. H. NeumanN
F. WOLF
K. YOSIDA

\section{SUPPORTING INSTITUTIONS}

\author{
UNIVERSITY OF BRITISH COLUMBIA \\ CALIFORNIA INSTITUTE OF TECHNOLOGY \\ UNIVERSITY OF CALIFORNIA \\ MONTANA STATE UNIVERSITY \\ UNIVERSITY OF NEVADA \\ NEW MEXICO STATE UNIVERSITY \\ OREGON STATE UNIVERSITY \\ UNIVERSITY OF OREGON \\ OSAKA UNIVERSITY \\ UNIVERSITY OF SOUTHERN CALIFORNIA
}

\author{
STANFORD UNIVERSITY \\ UNIVERSITY OF TOKYO \\ UNIVERSITY OF UTAH \\ WASHINGTON STATE UNIVERSITY \\ UNIVERSITY OF WASHINGTON \\ AMERICAN MATHEMATICAL SOCIETY \\ CHEVRON RESEARCH CORPORATION \\ TRW SYSTEMS \\ NAVAL ORDNANCE TEST STATION
}

Mathematical papers intended for publication in the Pacific Journal of Mathematics should be typewritten (double spaced). The first paragraph or two must be capable of being used separately as a synopsis of the entire paper. It should not contain references to the bibliography. Manuscripts may be sent to any one of the four editors. All other communications to the editors should be addressed to the managing editor, Richard Arens at the University of California, Los Angeles, California 90024.

50 reprints per author of each article are furnished free of charge; additional copies may be obtained at cost in multiples of 50 .

The Pacific Journal of Mathematics is published monthly. Effective with Volume 16 the price per volume (3 numbers) is $\$ 8.00$; single issues, $\$ 3.00$. Special price for current issues to individual faculty members of supporting institutions and to individual members of the American Mathematical Society: $\$ 4.00$ per volume; single issues $\$ 1.50$. Back numbers are available.

Subscriptions, orders for back numbers, and changes of address should be sent to Pacific Journal of Mathematics, 103 Highland Boulevard, Berkeley 8, California.

Printed at Kokusai Bunken Insatsusha (International Academic Printing Co., Ltd.), 7-17, Fujimi 2-chome, Chiyoda-ku, Tokyo, Japan.

PUBLISHED BY PACIFIC JOURNAL OF MATHEMATICS, A NON-PROFIT CORPORATION

The Supporting Institutions listed above contribute to the cost of publication of this Journal, but they are not owners or publishers and have no responsibility for its content or policies. 


\section{Pacific Journal of Mathematics}

A. A. Aucoin, Diophantine systems ............................. 419

Charles Ballantine, Products of positive definite matrices. I ............... 427

David Wilmot Barnette, A necessary condition for d-polyhedrality ............ 435

James Clark Beidleman and Tae Kun Seo, Generalized Frattini subgroups of finite groups ......................................... 441

Carlos Jorge Do Rego Borges, A study of multivalued functions ............. 451

William Edwin Clark, Algebras of global dimension one with a finite ideal

lattice ...............................................

Richard Brian Darst, On a theorem of Nikodym with applications to weak convergence and von Neumann algebras .........................

George Wesley Day, Superatomic Boolean algebras .....................

Lawrence Fearnley, Characterization of the continuous images of all

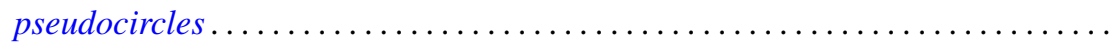

Neil Robert Gray, Unstable points in the hyperspace of connected subsets....... 515

Franklin Haimo, Polynomials in central endomorphisms .................. 521

John Sollion Hsia, Integral equivalence of vectors over local modular lattices . . . . 527

Jim Humphreys, Existence of Levi factors in certain algebraic groups .......... 543

E. Christopher Lance, Automorphisms of postliminal $C^{*}$-algebras ............ 547

Sibe Mardesic, Images of ordered compacta are locally peripherally metric . . . . 557

Albert W. Marshall, David William Walkup and Roger Jean-Baptiste Robert Wets,

Order-preserving functions: Applications to majorization and order

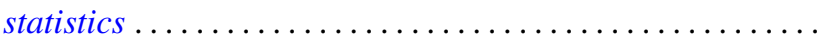

Wellington Ham Ow, An extremal length criterion for the parabolicity of

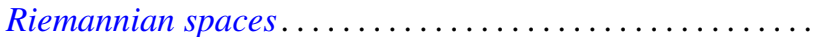

585

Wellington Ham Ow, Criteria for zero capacity of ideal boundary components of

Riemannian spaces...................................... 591

J. H. Reed, Inverse limits of indecomposable continua .................. 597

Joseph Gail Stampfli, Minimal range theorems for operators with thin spectra . . . 601

Roy Westwick, Transformations on tensor spaces..................... 613

Howard Henry Wicke, The regular open continuous images of complete metric

spaces ........................................... 621

Abraham Zaks, A note on semi-primary hereditary rings .............. 627

Thomas William Hungerford, Correction to: "A description of $\operatorname{Mult}_{i}\left(A^{1}, \cdots, A^{n}\right)$

by generators and relations" ............................. 629

Uppuluri V. Ramamohana Rao, Correction to: "On a stronger version of Wallis' formula".............................................. 629

Takesi Isiwata, Correction: "Mappings and spaces" ................... 630

Henry B. Mann, Josephine Mitchell and Lowell Schoenfeld, Correction to:

"Properties of differential forms in $n$ real variables" .... . .

James Calvert, Correction to: "An integral inequality with applications to the

Dirichlet problem"............................. 